\title{
BATISTAS ESLAVOS EM CURITIBA: RELIGIÃO E ETNICIDADE
}

Antônio César Camargo Miranda Orientação: Sergio Odilon Nadalin

PALAVRAS-CHAVE: missionarismo; batistas eslavos; etnicidade.

A existência de grupos religiosos denominados “eslavos” é muito intrigante, pois a união dessas várias etnias, nada homogêneas entre si, não pode ser feita de forma simples. As várias diferenças históricas, diversidades lingüísticas, e suas distinções a respeito da religião, mostram que os "eslavos" diferem-se muito. Dentre todos esses fatores, a marca religiosa acaba por separá-los ainda mais: os poloneses são católicos de rito latino, os russos e ucranianos pertencem ao catolicismo ortodoxo e partes dos ucranianos acabaram tornando-se católicos uniatas. Porém, ocorreu na cidade de Curitiba a união de todas essas etnias heterogêneas, em um mesmo espaço religioso.

Pode-se observar a existência de cerimônias, na capital paranaense, que forneçam "assistência espiritual" a estas etnias que é anterior ao início do desenvolvimento de suas atividades. Porém, estes foram alvo do missionarismo dos batistas e acabaram se organizando em torno de uma profissão de fé comum, que não se enquadra entre o catolicismo de rito latino, ortodoxo, ou o uniatismo.

A expansão da religião batista no mundo deve-se a processos migratórios de "professantes" dessa denominação e prática de um missionarismo característico. A denominação batista instala-se na América do Norte e no continente europeu a partir de movimentos imigratórios decorrentes de perseguições religiosas ocorridas na Inglaterra no século XVII. Os batistas entendiam que deveria haver liberdade absoluta em relação a questões religiosas. Assim sendo, Igreja e Estado deveriam ser dissociados. Aliado a essa questão política, essas pessoas acreditavam que poderiam criar uma Igreja baseada em princípios neotestamentários, ministrando o batismo por 
submersão apenas àqueles que cressem em Cristo e no Evangelho. O batismo infantil, ou por aspersão, não seria considerado como bíblico, e nesses casos há a necessidade do "rebatismo" - daí a denominação "batista". Partindo do princípio de que a Bíblia é sua única regra de fé e prática, os batistas entendem que estes princípios não devem ser negligenciados. Esta teria sido uma razão para a emigração de batistas, uma vez que almejavam formar Igrejas onde tais questões fossem respeitadas.

À medida que os imigrantes iam chegando nos Estados Unidos e na Europa, as igrejas foram surgindo, sem começar de um centro específico, mas sim a partir de várias comunidades que aos poucos foram crescendo. Tendo como preocupação expandir suas crenças, essa denominação inicia um trabalho missionário voltado ao envio de indivíduos especificamente com o objetivo de propagar seus ideais. Assim William Carey e John Thomas, em 1793, são mandados a Índia, dando início as Missões Protestantes Modernas ${ }^{1}$. Após estes primeiros missionários, fez-se necessária a criação de Convenções e Juntas Missionárias que reunissem as igrejas batistas no intuito de angariar fundos para criar e manter trabalhos de difusão de sua fé em diversos locais. Tais instituições proporcionaram a manutenção de vários missionários espalhados por múltiplos territórios ${ }^{2}$ e através de uma teologia expansionista de missão crescente, o missionarismo batista foi sendo ampliado durante o século XIX, chegando inclusive ao Brasil.

Uma das Juntas Missionárias de maior expressão foi a Junta de Richmond, criada no ano de 1845, ligada à Convenção Batista do Sul dos Estados Unidos. Seu objetivo era enviar e sustentar missionários em locais onde ainda não havia pessoas que conhecessem ou tivessem algum tipo de contato real e mais profundo com os ensinamentos evangélicos. No entender desta instituição, o

\footnotetext{
${ }^{1}$ PEREIRA, José Reis. História dos Batistas no Brasil. Rio de Janeiro: JUERP, 2001, p. 52.

${ }^{2}$ Pontos da África, América e Ásia, com uma crescente demanda ao enviar pessoas para a China. (Ibid., p. 57-58)
} 
Brasil era um país que se encaixava nessa condição, pois o catolicismo era julgado como idólatra, apegado ao culto a Maria e aos santos. Nessas circunstâncias, apesar do Brasil ser considerado, num âmbito geral, uma nação cristã, fazia-se necessária a introdução de um “evangelho puro” e a conversão de todos os católicos, não só brasileiros, mas de todo o mundo ${ }^{3}$.

Nessa perspectiva de pregar a palavra de Deus aos brasileiros, essa instituição envia o missionário Thomas Jefferson Bowen, em 1860, para propagar o evangelho na cidade do Rio de Janeiro. Após seu insucesso, devido à "falta de um planejamento que lhe norteasse o trabalho”, alto custo de vida que dificultava seu sustento e sua saúde que já se encontrava debilitada, agravada com o clima da cidade, o missionário regressou aos Estados Unidos ${ }^{4}$. Em seguida, outros grupos de batistas a chegaram ao Brasil. Teriam sido imigrantes oriundos do sul dos Estados Unidos, em decorrência da Guerra de Secessão, e que se estabeleceram em Santa Bárbara, na província de São Paulo. Na colônia que se organizou, foram criadas algumas igrejas no ano de 1871, sendo uma batista. Assim, a primeira Igreja dessa denominação fundada no Brasil tinha a intenção de atender apenas aos imigrantes, sendo seus cultos realizados na língua inglesa ${ }^{5}$. É possível observar que esta comunidade também se preocupa em apresentar suas crenças aos brasileiros e faz algumas solicitações a Junta de Richmond para que se enviem missionários a região ${ }^{6}$.

A Primeira Igreja Batista criada com o intuito de apresentar os ensinamentos da denominação aos brasileiros foi fundada em 1882, em Salvador, na Bahia. Após a fundação dessa comunidade e seu desenvolvimento, os missionários resolveram expandir o trabalho em outras regiões. Auxiliados pela chegada de mais missionários e,

\footnotetext{
${ }^{3}$ Ibid., pp. 67-68.

${ }^{4}$ Ibid., p. 68.

${ }^{5}$ Ibid., p. 69.

${ }^{6}$ KEIDANN, D. M. Uma Introdução à história dos batistas no Rio Grande do Sul numa perspectiva transcultural. Minas Gerais: IEPG, 1996. p. 69.
} 
conseqüentemente, a propagação decorrente do evangelho, várias comunidades batistas foram sendo criadas por todo país. Assim, os primeiros evangelistas a chegarem à Curitiba, Manoel Virgínio de Souza e Robert Pettigrew, provinham de trabalhos que estavam sendo implantados ao longo do litoral paranaense. Abrindo uma nova frente de atuação na capital do estado, no ano de 1914, organizou-se a Primeira Igreja Batista de Curitiba, constituída por nove membros. Os cultos eram realizados na casa do missionário Manoel Virgínio de Souza e, com o crescimento da comunidade, fez-se necessária à compra de um local próprio para a acomodação dos membros da comunidade. Auxiliados por um obreiro recém chegado de São Paulo, Arthur Beriah Deter, foi possível a aquisição de um terreno na rua Visconde de Guarapuava, esquina com a rua Desembargador Westphalen. A Igreja, então com cerca de 115 membros, terminou a construção e inaugurou seu templo em 1924 ${ }^{7}$. Em seguida, a comunidade continuou crescendo com a visão de prosseguir espalhando o evangelho por toda a cidade, criando congregações que virariam igrejas constituídas.

Neste período, também grupos de batistas provindos do leste europeu se instalaram no interior do Estado de São Paulo. Essas pessoas queixavam-se das dificuldades materiais e "espirituais" em que se encontravam os que viviam na União Soviética. Cerca de 50 famílias, divididas em dois grupos, vieram dessa região e chegaram ao Brasil em 1926. Um desses imigrantes era o pastor batista Simeon Molochenco, que alguns dias após sua chegada ao interior de São Paulo, dirigiu-se a capital do estado. Estabeleceu contato com os missionários norte-americanos que lá estavam e que já haviam fundado o Colégio Batista Brasileiro, com intuito de evangelizar os brasileiros através da educação. Molochenco utilizou as instalações do colégio para organizar, em 1926, a Primeira Igreja Evangélica Batista Russa de São Paulo e desenvolver um trabalho missionário entre os eslavos. Sua visão missionária fez com que a propagação do

${ }^{7}$ SOUZA, Sóstenes Borges de. Enciclopédia Batista Brasileira. Salvador: Artios, 1996, p. 77. 
evangelho fosse difundida no interior de São Paulo e no estado do Paraná.

Esta comunidade enviava periodicamente missionários ao interior do estado do Paraná e a Curitiba, com intuito de pregar o evangelho a todos os eslavos que se encontrassem nessas regiões. Como resultado, algumas pessoas receberam a "mensagem da salvação de Cristo" e, em consequiência, batizaram-se e tornaram-se membros da Primeira Igreja Batista de Curitiba. Após ingressarem nesta comunidade, tinham interesse em se reunir nos domingos à tarde, separadamente dos brasileiros, para realizarem cultos falando seu próprio idioma ${ }^{8}$; junto aos brasileiros, muitos desses estrangeiros (ucranianos, russos e poloneses) tinham dificuldade em entender e assimilar o que era passado através das mensagens pregadas e das músicas contidas no culto em português. De forma que, separados dos brasileiros, sentiam-se mais à vontade para desenvolverem seus trabalhos eclesiásticos. Deste modo, no ano de 1934, verificava-se a organização da Congregação Eslava de Curitiba, ligada a Primeira Igreja Evangélica Batista Russa de São Paulo, que tinha como intenção congregar e exercer o missionarismo apenas entre "eslavos" e passou a agrupar em um mesmo espaço religioso diferentes grupos étnicos como russos, poloneses e ucranianos.

Os "batistas eslavos" identificaram-se e foram identificados pelos brasileiros na base de uma dicotomia nós/eles, estabelecidos a partir de traços culturais que se supõe derivados de uma origem comum $^{9}$. Uma das formas pela qual houve identificação entre estes eslavos foi a proximidade de seus idiomas, havendo melhor compreensão entre as línguas russa, ucraniana e polonesa do que com

8 Estes “eslavos”, constituídos de russos, ucranianos e poloneses, pouco compreendiam o português. Como as línguas de origem "eslava” são parecidas entre si, foi possível a conversação e emprego do próprio idioma de cada etnia em seus trabalhos religiosos. Assim todos conversavam utilizando as línguas russa, ucraniana e polonesa, deixando o português de lado.

${ }^{9}$ POUTIGNAT, Philippe; STREIFF-FENART, Jocelyne. Teorias da Etnicidade; seguido de Grupos Étnicos e suas Fronteiras, de Fredrik Barth. São Paulo: Fundação Editora da UNESP, 1998, p. 141. 
o português. Ao não se expressarem corretamente e não entenderem por completo a língua portuguesa, falando outros idiomas que os brasileiros não entendiam, foram tratados como estrangeiros e denominados como “irmãos ukrainos”. ${ }^{10}$ Deste modo, os membros do grupo eslavo demarcavam uma "fronteira étnica” através da língua ${ }^{11}$. Mas, nesse primeiro momento, não foi apenas esse fator que os diferenciou dos brasileiros ${ }^{12}$. Todos esses russos, ucranianos e poloneses eram "recém-convertidos" e ainda não tinham amplo conhecimento de todas as peculiaridades da doutrina batista, sendo necessário "mais tempo na fé" para que fossem doutrinados e conhecessem melhor os mandamentos da denominação.

Na década de 1930, a comunidade eslava não tinha muitos membros. Ao estar em contato com os brasileiros da Primeira Igreja Batista de Curitiba, assim autodenominaram-se para abranger todas as especificidades étnicas do grupo. A partir da segunda metade da década de 1940, os batistas eslavos já tinham adquirido um local próprio para realizarem seus cultos e, com maior número de pessoas, iniciou-se uma proposta diferente para a Congregação. O crescimento da comunidade abriu a possibilidade de que cada grupo constituísse trabalho próprio, pois a identificação como "eslavos" deixou de abranger todas as especificidades étnicas existentes no interior da comunidade. Ou seja, o aumento do número de pessoas fez com que rivalidades entre russos, ucranianos e poloneses ressurgissem, pois não constituíam uma única tradição, mas abrigavam diferenças histórico-culturais agudas ${ }^{13}$. Sendo difícil a adesão por parte de todos

\footnotetext{
10 Ata da Primeira Igreja Batista de Curitiba, Livro 4, p. 13.

${ }^{11}$ POUTIGNAT; STREIFF-FENART, op. cit., p. 51.
}

12 Nas análises discutidas por POUTIGNAT e STREIFF-FENART, tanto a língua, como território, ou outros atributos em comum, não podem ser fatores únicos pelos quais um grupo étnico forma fronteiras para distinguir-se dos demais grupos que estão à volta. Estes elementos apenas representam atributos étnicos quando utilizados como marcadores de pertença a um grupo, por aqueles que reivindicam uma origem comum. (Ibid., p. 163)

13 ANDREAZZA, Maria Luiza. Paraíso das Delícias. Estudo de um grupo imigrante Ucraniano (1895-1995). Curitiba, 1996, p. 79. 
os membros num mesmo propósito de continuarem a exercer suas atividades em conjunto, alguns poloneses retiraram-se da comunidade para criar um trabalho à parte. Da mesma forma, alguns ucranianos organizaram um grupo separado. Deste modo, os que haviam saído da Congregação Eslava de Curitiba acreditavam que russos, poloneses e ucranianos, ao separarem-se, teriam mais liberdade para regerem suas atividades religiosas conforme língua e tradições culturais próprias.

A Congregação Eslava de Curitiba, apesar de todas estas dissensões, continuou a agregar grupos das mencionadas origens, porém com número de membros reduzido. Os indivíduos que resolveram continuar na comunidade ainda identificavam-se como "eslavos" e continuaram empregando seus cultos na língua russa, polonesa e ucraniana. Deste modo, visavam manter um mandamento contido no Novo Testamento: conservar a unidade da Igreja num "espírito de paz e amor", para que a comunidade propagasse a salvação de Cristo a todos os eslavos ${ }^{14}$. Assim deram prosseguimento a suas atividades religiosas.

No ano de 1949, chega à cidade de Curitiba uma nova leva de imigrantes eslavos. Eram refugiados da Segunda Guerra que estavam fora das fronteiras de seus países de origem, e não queriam mais regressar à sua terra natal. Ao chegarem à capital paranaense, entraram em contato com a pregação do evangelho praticado pelos "batistas eslavos". Muitos aceitaram a mensagem trazida por esse grupo e aderiram à nova religião, fazendo com que o número de membros da comunidade voltasse a crescer. Com a conservação dos trabalhos missionários na cidade, no ano de 1955 esta congregação organizou-se e passou à forma de Igreja constituída, com o nome de Primeira Igreja Evangélica Batista Eslava de Curitiba ${ }^{15}$.

${ }^{14}$ Ata da Congregação de Curitiba da Primeira Igreja Evangélica Batista Russa de
São Paulo, Livro 1, 17/10/1948.
${ }_{15}$ A congregação pode organizar-se em igreja a partir do momento em que consiga
manter-se fisicamente, sustentando todos os seus gastos financeiros, e
"espiritualmente", tendo pastor próprio ou algum outro responsável que fique à
frente de suas atividades eclesiásticas. Constitui-se, portanto, igreja ao preencher
essas condições e os indivíduos demonstrem vontade para que possa efetivar-se a 
A partir da década de 1960, o número de membros dessa igreja continuou a diminuir. Os mais jovens já não se identificavam mais com a "forma eslava" do culto. Ao serem empregadas apenas as línguas russas, polonesas e ucranianas, estes começaram a ficar fora das reuniões, pois muitos deles já não entendiam bem estes idiomas. Deste modo, alguns se dirigiram para igrejas batistas brasileiras, outros adentraram comunidades evangélicas de outras denominações e houve aqueles que renunciaram a fé dos seus pais, não se ligando a nenhum grupo religioso. Por outro lado, os membros fundadores do trabalho entre os eslavos começaram a ficar com uma idade avançada e, aos poucos, o falecimento destes contribuiu ainda mais para a diminuição da comunidade.

A partir da década de 1970, os cultos começaram a incorporar partes da sua liturgia empregada em português, mas as línguas russa, ucraniana e polonesa ainda se faziam muito presentes. Porém, como a comunidade estava reduzida, a liderança da igreja iniciou uma discussão para a mudança no formato dos trabalhos eclesiásticos empregados. A antiga idéia de propagar o evangelho apenas entre os eslavos não fazia tanto sentido, pois havia poucas pessoas dessa etnia dentro e fora da comunidade. Para que a Igreja voltasse a crescer era necessário empregar uma nova direção aos trabalhos da comunidade. Através dessa pretensão, a Primeira Igreja Evangélica Batista Eslava de Curitiba muda seu nome, no ano de 1978, para Igreja Batista da Água Verde, tendo por objetivo atender as "necessidades espirituais" dos brasileiros e não mais dos eslavos da cidade de Curitiba. Com uma reestruturação nas formas de culto e ritos existentes até então, o português torna-se a única língua utilizada em todas as atividades da "nova” Igreja. Assim, os batistas remanescentes nessa comunidade, dão início a uma nova forma de trabalho: propagar o evangelho entre os brasileiros da capital paranaense.

organização. Na medida em que estejam sujeitos à doutrina batista, seus artigos de fé, os ensinos bíblicos que seguem, sua responsabilidade para com a denominação batista e os estatutos da igreja que expostos não devem contrariar a crença doutrinária da denominação, surge uma nova comunidade batista. 
A imigração de batistas do leste europeu fez com que houvesse uma preocupação específica de um trabalho missionário que pudesse propagar o evangelho a todos os eslavos presentes no Brasil. Assim, estes batistas, situados na cidade de São Paulo, iniciam seu missionarismo na cidade de Curitiba e aos poucos conseguem novos adeptos a sua religião. Na medida em que alguns "eslavos" foram aceitando a mensagem que lhes era trazida, começaram a freqüentar uma Igreja Batista, porém formada por brasileiros. Assim, como formavam um grupo a parte, foi estabelecida a definição de um grupo étnico eslavo, que aos poucos foi se dissociando e desenvolvendo trabalhos próprios.

Visando dar continuidade à propagação de sua fé, os batistas eslavos, acabaram identificando-se como pessoas de uma mesma origem. Porém, com o crescimento da comunidade, as especificidades étnicas acabaram por despertar suas diferenças histórico-culturais. Com a possibilidade de cada etnia desenvolver seu próprio trabalho, russos, ucranianos e poloneses iniciaram um processo de desagregação. Os membros que resolveram continuar na comunidade, ainda identificavam-se como eslavos e conseguiram conviver com suas diferenças, mantendo "a união da Igreja”. 